\title{
Differential Requirements of MyD88 And TRIF Pathways in TLR4-mediated Immune Responses in Murine B Cells
}

\author{
Tsutomu Yanagibashi ${ }^{\mathrm{a}, \mathrm{b}, 1}$, Yoshinori Nagai ${ }^{\mathrm{a}, \mathrm{c}, 1}$, Yasuharu Watanabe ${ }^{\mathrm{a}}$, Masashi Ikutani ${ }^{\mathrm{a}}$, \\ Yoshikatsu Hirai $^{\mathrm{a}}$, and Kiyoshi Takatsu $\mathrm{a}^{\mathrm{a}, \mathrm{b}}$
}

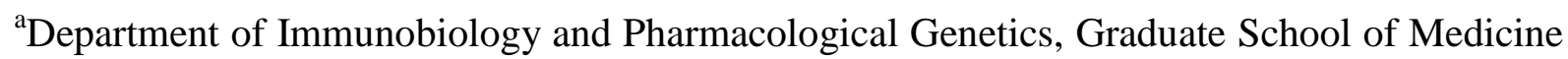
and Pharmaceutical Science for Research, University of Toyama, 2630 Sugitani, Toyama-shi, Toyama 930-0194, JAPAN

${ }^{\mathrm{b}}$ Toyama Prefectural Institute for Pharmaceutical Research, 17-1 Nakataikouyama, Imizu City, Toyama 939-0363, JAPAN

' JST, PRESTO, 4-1-8 Honcho, Kawaguchi, Saitama 332-0012, JAPAN

${ }^{1}$ These authors contributed equally to this work.

Correspondence: Yoshinori Nagai, M.D., Ph.D. and Kiyoshi Takatsu, Ph.D.

Department of Immunobiology and Pharmacological Genetics, Graduate School of Medicine and Pharmaceutical Science for Research, University of Toyama

2630 Sugitani, Toyama-shi, Toyama 930-0194, Japan

Phone: +81-76-434-7673

Fax: +81-76-434-5009

E-mail: ynagai@med.u-toyama.ac.jp (Y.N.), takatsuk@med.u-toyama.ac.jp (K.T.) 


\section{Abbreviations}

Aicda: activation-indeced cytidine deaminase

CSR: class switch recombination

IL-4 receptor: IL-4R

MD-2: myeloid differentiation protein 2

MPLA: monophosphoryl lipid A

RP105: radioprotective 105

TI: T cell -independent

TIR: Toll/IL-1R

TNP: trinitrophenyl

TRAM: TRIF-related adaptor molecule

TRIF: TIR-domain-containing adaptor-inducing interferon- $\beta$

WT: wild-type 


\begin{abstract}
LPS stimulates the TLR4/Myeloid differentiation protein-2 (MD-2) complex and promotes a variety of immune responses in B cells. TLR4 has two main signaling pathways, MyD88 and Toll/IL-1R (TIR)-domain-containing adaptor-inducing interferon- $\beta$ (TRIF) pathways, but relatively few studies have examined these pathways in B cells. In this study, we investigated MyD88- or TRIF-dependent LPS responses in B cells by utilizing their knockout mice. Compared with wild-type (WT) B cells, MyD $88^{-/-} \mathrm{B}$ cells were markedly impaired in up-regulation of CD86 and proliferation induced by lipid A moiety of LPS. TRIF ${ }^{-/}$B cells were also impaired in these responses compared with WT B cells, but showed better responses than MyD88 ${ }^{-/-}$B cells. Regarding class switch recombination (CSR) elicited by lipid A plus IL-4, MyD88 ${ }^{-/-}$B cells showed similar patterns of CSR to WT B cells. However, $\mathrm{TRIF}^{-/-} \mathrm{B}$ cells showed the impaired in the CSR. Compared with WT and MyD88 ${ }^{-/-} \mathrm{B}$ cells, $\mathrm{TRIF}^{-/-} \mathrm{B}$ cells exhibited reduced cell division, fewer $\mathrm{IgG} 1^{+}$cells per division, and decreased activation-induced cytidine deaminase (Aicda) mRNA expression in response to lipid A plus IL-4. Finally, IgG1 production to trinitrophenyl (TNP)-LPS immunization was impaired in $\mathrm{TRIF}^{-/-}$mice, while MyD88 $8^{-/-}$mice exhibited increased IgG1 production. Thus, MyD88 and TRIF pathways differently regulate TLR4-induced immune responses in B cells.
\end{abstract}

Key words: Keywords: CSR; IL-4; innate immunity; LPS; MyD88; TLR; TRIF 


\section{Introduction}

B cells play an essential role in the development of antibody responses to pathogens [1]. These are regulated by signals delivered via several mediators including BCR and TLR family proteins. The exposure of mouse B cells to TLR ligands, such as LPS, promotes a combination of responses in B cells, including up-regulation of co-stimulatory molecules, cell proliferation, and class switch recombination (CSR) [2]. In the process of CSR, B cells integrate signals via TLRs and cytokine receptors. For instance, IL-4 prominently induces CSR primarily to IgG1 and IgE in the presence of TLR ligands, including LPS, CpG, 8-mercaptoguanosine, loxoribine or poly(I:C) [3-6]. TGF- $\beta$ is a critical cytokine for CSR to IgA [7]. By contrast, CSR to IgG3 is induced by LPS stimulation alone [8].

To deliver a signal, TLRs require a variety of Toll/IL-1R (TIR) domain containing adaptor molecules including MyD88 and TIR-domain-containing adaptor-inducing interferon- $\beta$ (TRIF). MyD88 is recruited by TLR4 following LPS ligation and has an important role for the early activation of NF- $\mathrm{BB}$ to govern the induction of pro-inflammatory cytokines [9]. On the other hand, TRIF is recruited by TRIF-related adaptor molecule (TRAM) and has a critical role for the late activation of $\mathrm{NF}-\kappa \mathrm{B}$ as well as the activation of IRF3, which is important for the induction of IFN-inducible genes [10]. However, analyses of these pathways have been performed in mainly macrophages and dendritic cells. TLR4 was the first TLR to be identified and its extracellular domain forms a heterodimeric complex with the secreted myeloid differentiation protein-2 (MD-2) $[11,12]$. Neither TLR $4^{-/-}$or MD- $2^{-/-}$ mice respond to LPS, so the TLR4/MD-2 complex is essential for LPS responses [13,14]. TLR4 activates both MyD88 and TRIF pathways, but little is known how B cells use these signaling pathways differently in response to LPS.

Several in vivo studies have suggested a role for MyD88 in humoral immunity. MyD88 pathway in B cells is required for $\operatorname{IgM}$ and $\operatorname{IgG} 2 \mathrm{c}$ production in response to adjuvants, which 
include TLR ligands [15]. However, other studies revealed that MyD88-deficient B cells can promote normal primary antibody production after immunization with certain adjuvants [16]. In addition, B cell-intrinsic TLR-MyD88 pathway has been implicated in the production of anti-DNA antibodies in a mouse SLE model [17]. Therefore, MyD88 pathway contributes to antibody responses depending on the type of immune challenge and disease models. However, much less is known about roles of TRIF in antibody responses. A recent paper has reported that TRIF is essential for LPS plus IL-4-driven CSR to IgE by inducing sustained NF- $\kappa \mathrm{B}$ activation in B cells [18].

We have now utilized gene-targeted mice to explore the importance of MyD88- or TRIF-dependent LPS responses in B cells. We found that MyD88 and TRIF pathways differently regulate TLR4 signals in spleen B cells. MyD88 pathway is sufficient for a variety of B cell responses induced by TLR4 stimulation alone. TRIF signaling is required but not sufficient for these responses. Intriguingly, TRIF pathway plays an important role in functional coupling between TLR4 signaling and IL-4 receptor (IL-4R) signaling to induce cell division, Aicda mRNA expression, and CSR. 


\section{Materials and Methods}

\subsection{Mice}

C57BL/6 mice were purchased from Japan SLC (Hamamatsu, Japan) and were used at 8 to 10 weeks of age. C57BL/6, TLR4 ${ }^{-/-}[13], \mathrm{MyD}^{-/-}$[19] and $\mathrm{TRIF}^{-/-}$[10] mice were maintained in microisolator cages under specific pathogen-free conditions, and maintained in the animal facility of University of Toyama. The genetic backgrounds of these knockout mice were C57BL/6. All experiments were performed according to the guidelines for the care and treatment of experimental animals at University of Toyama (Approved No. S-2010MED-26).

\subsection{Reagents}

Lipid A from Salmonella minnesota was purchased from Sigma-Aldrich (St. Louis, MO). CpG-B was purchased from Hokkaido System Science (Japan). Pam ${ }_{3} \mathrm{CSK}_{4}$ and poly(I:C) were purchased from InvivoGen (San Diago, CA). Recombinant mouse IL-4, IL-5, TGF- $\beta$, and purified anti-mouse CD40 mAb were purchased from R \& D Systems (Minneapolis, MN). CFSE was purchased from Molecular Probes (Carlsbad, CA). APC-conjugated streptavidin was purchased from BD Bioscience (San Diago, CA). Trinitrophenyl (TNP)-LPS and TNP-BSA were purchased from Biosearch Technologies. Purified anti-mouse RP105 mAb (clone RP/14) [20] was purchased from eBioscience (San Diago, CA). Purified anti-mouse TLR4 mAb (clone UT12) were prepared as previously described [21].

\subsection{Flow Cytometry}

The following antibodies for flow cytometry were purchased from BD Bioscience: biotinylated anti-CD43 (clone S7), FITC- or APC-conjugated anti-CD45R/B220 (clone RA3-6B2), biotinylayed anti-IL-4R $\alpha$ (clone mIL4R-M1), Alexa647-conjugated anti-STAT6 (pY641) (clone J71-773.58.11), PE-conjugated anti-mouse IgG1 (clone A85-1), 
FITC-conjugated anti-mouse IgA (clone C10-3), biotinylated anti-mouse IgG3 (clone R40-82). PE-conjugated anti-CD86 (clone GL1) was purchased from eBioscience.

The cells $\left(1 \times 10^{5}\right)$ were incubated with purified anti-mouse Fc $\gamma \mathrm{R}$ (clone 2.4G2) to block binding of the labeled Abs to FcyR. After 15 min, the cells were stained with predetermined optimal concentrations of the respective Abs. 7-amino-actinomycin D (7-AAD) (BD Bioscience) was used to exclude dead cells. Flow cytometry analyses were conducted on a FACSCanto (Becton Dickinson \& Co., Mountain View, CA), and the data were analyzed with Flowjo software (Treestar, San Carlos, CA).

\section{$2.4 \mathrm{~B}$ cell preparation and proliferation in vitro}

Spleen cells were prepared from 8 to 10 -wk old mice, and their B cells were isolated by magnetic depletion of cells other type with biotinylated anti-CD43 and Streptavidin magnetic microbeads (Miltenyi Biotec, Bergisch Gladbach, Germany). The purified B cells contained $>95 \%$ B $220^{+}$cells, as assessed by flow cytometry using the FACSCanto. For ${ }^{3} \mathrm{H}$-Thymidine uptake, B cells were cultured as described previously [22,23].

For the measurement of cell division, B cells were stained with CFSE. Cells were suspended in RPMI containing $1 \mu \mathrm{M}$ CFSE, and incubated at $37^{\circ} \mathrm{C}$ for $10 \mathrm{~min}$. Cells were washed with $8 \%$ FCS-RPMI, and cultured with their respective stimuli at a density of $1 \times 10^{6}$ cells $/ \mathrm{ml}$. The number of cell division was analyzed by FACSCanto.

\subsection{ELISA}

Purified B cells ( $1 \times 10^{5}$ per $200 \mu \mathrm{l}$ per well) were cultured in a 96-well plate in RPMI 1640 medium (Life Technologies, Grand Island, NY) supplemented with 10\% heat-inactivated FCS, $50 \mu \mathrm{M}$ 2-ME, penicillin $(50 \mathrm{U} / \mathrm{ml})$, and streptomycin $(50 \mu \mathrm{g} / \mathrm{ml})$. Stimulants were added at the same time the cells were plated. Each culture was set-up in triplicate. The Ig concentration 
in the culture supernatants was titrated by ELISA. Briefly, ELISA plates were coated with unlabeled goat anti-mouse Ig $(\mathrm{H}+\mathrm{L})$ (Southern Biotech, Birmingham, AL). Igs in the B cells were detected with HRP-conjugated isotype-specific anti-mouse Igs (Southern Biotech). HRP-conjugated anti-mouse Ig was detected with o-phenylenediamine (Sigma-Aldrich) and ODs of $490 \mathrm{~nm}$ were determined with a Micro Plate Reader (Bio-Rad, Hercules, CA).

\subsection{Preparation of RNA and cDNA}

Total RNA was isolated with RNeasy mini kit (QIAGEN, Hilden, Germany) following the manufacture's instructions. RNA was reverse transcribed with a TaqMan Reverse Transcription Reagents (Applied Biosystems, Carlsbad, CA) following the manufacture's instructions.

\subsection{Real-time quantitative PCR}

Real-time quantitative PCR (RT-qPCR) was performed with a TaqMan Gene Expression Master Mix (Applied Biosystems) and analyzed with a Mx3000P (Agilent Technologies, Santa Clara, CA) following the manufacture's instructions. Relative transcript abundance was normalized for that of Hprt mRNA. The information for primers used for real-time PCR is listed in Supplementary Table 1.

\subsection{Determination of serum immunoglobulins and $A b$ responses in vivo}

C57BL/6, $\mathrm{TLR}^{-/}, \mathrm{MyD}^{-/-}$and $\mathrm{TRIF}^{-/-}$mice were immunized intraperitoneally with TNP-LPS (20 $\mu \mathrm{g} /$ mouse) in phosphate-buffered saline. The serum concentration of TNP-specific Abs at different time point was measured by ELISA. ELISA was performed by coating plastic plates with TNP-BSA, and serial dilutions were applied onto the plate. Bound antibodies were revealed by goat Abs specific each Ig isotype. To determine serum Ig titers, 
goat anti-mouse $\mathrm{Ig}(\mathrm{H}+\mathrm{L})$ (Southern Biotech) was coated instead of TNP-BSA.

\subsection{Statistical analysis}

Statistical significance was evaluated by one-way ANOVA followed by post-hoc Tukey test. 


\section{Results}

3.1 CD86 up-regulation and cell proliferation induced by lipid A alone are largely dependent on MyD88

We first investigated B cell responses to lipid A or other TLR ligands in WT, TLR4 ${ }^{-/}$,

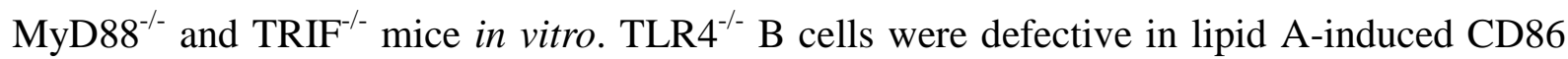
up-regulation and proliferation (Fig. 1A and 1B). These responses were impaired in MyD88 ${ }^{-/-}$ and $\mathrm{TRIF}^{-/-} \mathrm{B}$ cells. TRIF ${ }^{-/-} \mathrm{B}$ cells showed better response than MyD88 ${ }^{-/-} \mathrm{B}$ cells (Fig. 1A and B). In addition, we utilized agonistic anti-TLR4 mAb [21]. The mAb induced massive proliferation of WT B cells and gave similar results to the lipid A stimulation in MyD88 ${ }^{-{ }_{-}}$or $\mathrm{TRIF}^{-{ }^{-}}$B cells (Supplementary Fig. 1). MyD88 ${ }^{-{ }_{-}}$or $\mathrm{TRIF}^{-{ }^{-}}$B cells as well as WT B cells promoted spleen B cell proliferation in response to another TLR family protein radioprotective 105 (RP105) stimulation [20,23].

TLR2 and TLR9 trigger only MyD88 pathway. TLR2 ligand $\mathrm{Pam}_{3} \mathrm{CSK}_{4}$ - or TLR9 ligand CpG-B induced CD86 up-regulation and proliferation in WT, TLR4 ${ }^{-/-}$and $\mathrm{TRIF}^{-/-} \mathrm{B}$ cells, while MyD88 ${ }^{-/-}$B cells showed defective responses to these stimuli (Fig. 1A and 1B). The TLR3 ligand poly(I:C)-induced CD86 up-regulation was markedly attenuated in $\mathrm{TRIF}^{-/-} \mathrm{B}$ cells. We recorded no significant proliferative responses in poly(I:C)-stimulated WT B cells (data not shown). Anti-CD40-induced CD86-upregulation and proliferation were comparable in B cells from all strains of mice. These results suggest that B cell responses induced by TLR4 stimulation alone are largely dependent on MyD88 and partly dependent on TRIF.

\subsection{TRIF $^{-/-}$B cells are attenuated in CSRs to IgG1 and IgE elicited by lipid A plus IL-4}

Our experiments focused on potential functions for MyD88 and TRIF pathways on CSR.

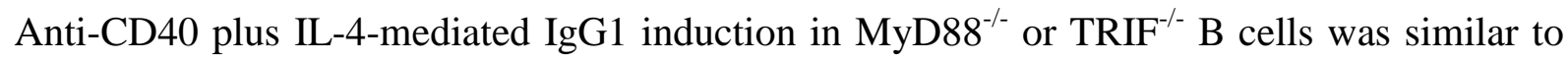
that in WT B cells (Fig. 2A). Lipid A plus IL-4 stimulation increased the percentages of IgG1 ${ }^{+}$ 
cells in WT B cells. Although the percentages of $\operatorname{IgG} 1^{+}$cells in MyD88 ${ }^{-/-}$B cells were higher than those in WT B cells, the induction of $\mathrm{IgGl}^{+}$cells was impaired in $\mathrm{TRIF}^{-/-} \mathrm{B}$ cells. $\mathrm{MyD}^{-{ }^{--}} \mathrm{B}$ cells were defective in the induction of $\mathrm{IgG} 1^{+}$cells induced by CpG-B plus IL-4 or $\mathrm{Pam}_{3} \mathrm{CSK}_{4}$ plus IL-4. We also confirmed the above findings by measuring IgG1 production (data not shown). B cells from all strains of mice produced comparable IgE by anti-CD40 plus IL-4 (Fig. 2B). Lipid A plus IL-4 stimulation induced IgE production in WT B cells. However, the highest concentration of lipid A $(1 \mu \mathrm{g} / \mathrm{ml})$ decreased IgE production in WT B cells compared with $0.1 \mu \mathrm{g} / \mathrm{ml}$ of lipid A. This may be due to low cell proliferation and decreased percentage of live cells (7-AAD-negative cells) in WT B cells stimulated with $1 \mu \mathrm{g} / \mathrm{ml}$ of lipid A compared with those stimulated with $0.1 \mu \mathrm{g} / \mathrm{ml}$ of lipid A (Fig. 1B and data not shown). As reported [18,24], IgE production was not observed in culture of $\mathrm{TLR}^{-/-}$or $\mathrm{TRIF}^{-{ }_{-}} \mathrm{B}$ cells in

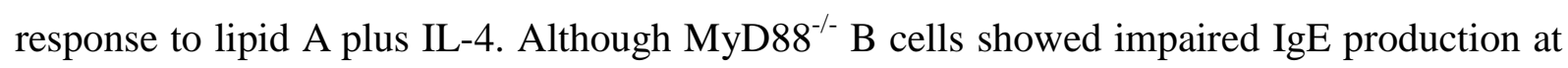
lower concentration of lipid A, they produced significant $\operatorname{IgE}$ at a higher concentration compared with WT B cells. These results imply that TLR4 plus IL-4-induced CSR to IgG1 and $\operatorname{IgE}$ is largely dependent on TRIF.

\subsection{TLR4 plus IL-4-elicited CSR to IgA is impaired in TRIF $^{-/-}$B cells}

We then asked whether TLR4 requires TRIF signaling to switch to other immunoglobulins (Igs) in B cells. Stimulation of WT B cells with lipid A plus TGF- $\beta$ induced $\operatorname{IgA}^{+}$cells and IgA production, but TLR4 ${ }^{-/-}$or MyD88 ${ }^{-/-}$B cells did not show these responses (Fig. 3A and 3B, data not shown). $\mathrm{TRIF}^{-/-} \mathrm{B}$ cells showed slightly impaired these responses compared with WT B cells. Although IL-5 stimulation increased the percentages of $\operatorname{IgA}^{+}$on lipid A plus TGF- $\beta$-stimulated B cells from all strains of mice (Fig. 3A), MyD88 ${ }^{-/-}$B cells showed defective IgA production even with the addition of IL-5 to lipid A plus TGF- $\beta$ stimulation (Fig. 3B). Further addition of IL-4 to lipid A plus TGF- $\beta$ plus IL-5-stimulated WT B cells 
increased the percentage of $\operatorname{IgA}^{+}$cells and IgA production (Fig. $3 \mathrm{~A}$ and 3B). In MyD88 $8^{-/-} \mathrm{B}$ cells, IgA production was dramatically augmented by addition of IL-4 to lipid A plus TGF- $\beta$ plus IL-5 stimulation (Fig. 3B). In contrast, these effects of IL-4 in $\mathrm{TRIF}^{-/-}$B cells were lower than those of WT B cells.

LPS stimulation alone increased the percentage of $\mathrm{IgG}^{+}$and $\mathrm{IgG} 3$ production in WT B cells (Fig. 3C and 3D). These responses were markedly impaired in MyD88 ${ }^{-/-} \mathrm{B}$ cells as well as $\mathrm{TLR}^{-/-} \mathrm{B}$ cells. $\mathrm{TRIF}^{-/-} \mathrm{B}$ cells also impaired these responses, but were better responder than $\mathrm{MyD}^{-/-}$B cells. As observed in Fig. 2B, the highest concentration of lipid A $(1 \mu \mathrm{g} / \mathrm{ml})$ decreased IgG3 production in WT B cells because of low cell proliferation and decreased percentage of live cells (Fig. 1B and data not shown). These results suggest that TLR4 plus IL-4-mediated CSR not only to IgG1 and IgE but also to IgA are mediated by TRIF signaling.

\subsection{TRIF is not directly involved in the regulation of IL-4R $\alpha$ expression and IL-4R signaling}

The above findings beg a question of whether TRIF protein is directly involved in IL-4R signaling. We then examined IL-4R $\alpha$ expression and IL-4-mediated events in WT, MyD88 ${ }^{-/-}$ and $\mathrm{TRIF}^{-/-} \mathrm{B}$ cells. The levels of IL-4R $\alpha$ expression on un-stimulated, lipid A- or anti-CD40-stimulated MyD88 $8^{-/-}$and $\mathrm{TRIF}^{-/-}$B cells were comparable to those on WT B cells (Fig. 4A). CD86 was up-regulated when WT B cells were stimulated with IL-4 (Fig. 4B).

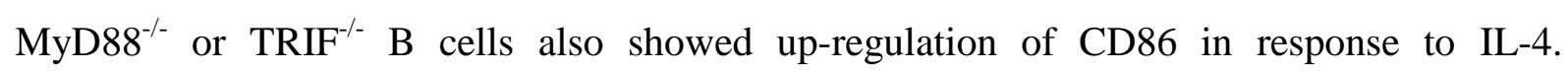
Furthermore, phosphorylated STAT6 (P-STAT6) in IL-4- or lipid A plus IL-4-stimulated ${\mathrm{MyD} 88^{-/-} \text {or TRIF }}^{-/-}$B cells was comparable to WT B cells (Fig. 4C). Thus, neither TRIF nor MyD88 is involved in the regulation of IL-4R $\alpha$ expression and IL-4R signaling.

\subsection{TRIF $^{-/-}$B cells are markedly attenuated in lipid A plus IL-4-induced cell division}


A number of previous studies have delineated that the appearance of class-switched cells occurs in a cell division-linked manner that does not depend on the time in culture or in cycle $[25,26]$. To clarify the reason for decreased number of class-switched cells in lipid A plus IL-4-treated TRIF $^{-/-}$B cells, cell division of CFSE-labeled cells was determined. Lipid

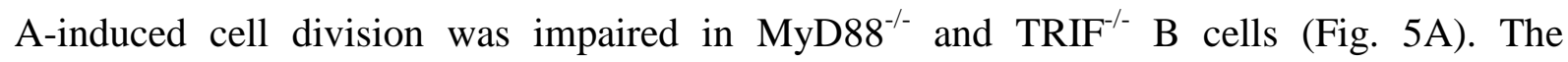
impairment was more apparent in $\mathrm{MyD}^{-/-} \mathrm{B}$ cells than $\mathrm{TRIF}^{-/-} \mathrm{B}$ cells. The addition of IL-4 slightly increased percentage of divided cells in lipid A-stimulated WT B cells. Intriguingly, the percentage of divided cells in lipid A-stimulated $\mathrm{MyD}^{-/-}$B cells was dramatically increased by 2 -fold by addition of IL-4. In contrast, the addition of IL-4 decreased percentage of divided cells in lipid A-stimulated $\mathrm{TRIF}^{-/-} \mathrm{B}$ cells. B cells from all strains of mice responded similarly to anti-CD40 plus IL-4 leading to the cell division.

We also determined the percentage of divided cells per generation. Lipid A stimulation alone produced large number of divided cells in the $>7^{\text {th }}$ division of WT and $\mathrm{TRIF}^{-/-} \mathrm{B}$ cells

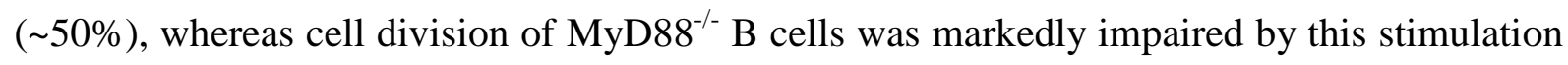
(Fig. 5B, left). The addition of IL-4 decreased the percentage of the $>7^{\text {th }}$ divided cells in lipid A-stimulated WT B cells $(\sim 20 \%)$, but increased the percentages of the $2^{\text {nd }}$ to $6^{\text {th }}$ divided cells in WT and MyD88 ${ }^{-/}$B cells (Fig. 5B, middle). Lipid A plus IL-4-stimulated TRIF ${ }^{-/}$B cells had lower percentages of the $3^{\text {rd }}$ to $6^{\text {th }}$ division and more non-divided cells $(\sim 45 \%)$ than WT

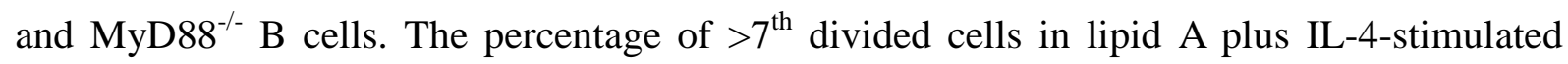
$\mathrm{TRIF}^{-/-} \mathrm{B}$ cells were comparable to those of WT and MyD88 $8^{-/-} \mathrm{B}$ cells. Similar percentages of divided cells per generation were seen in WT, $\mathrm{MyD}^{-{ }^{-/-}}$and $\mathrm{TRIF}^{-{ }^{-}-} \mathrm{B}$ cells in response to anti-CD40 plus IL-4 (Fig. 5B, right). Thus, TRIF is important for TLR4 plus IL-4-induced B cell division.

3.6 TRIF $^{-/-}$B cells are markedly attenuated in lipid A plus IL-4-induced rate of IgG1 ${ }^{+}$ 


\section{cells per generation and Aicda mRNA expression}

The impairment of CSR in TLR4 plus IL-4-stimulated TRIF $^{-/-}$B cells may be due to a result of altered cell division/differentiation, but may be due to suppression of a CSR machinery regulated by TRIF. Although $\mathrm{TRIF}^{-/-} \mathrm{B}$ cells weakly but substantially divided in response to lipid A plus IL-4, the population of $\mathrm{IgG1}^{+}$cells with division was remarkably reduced (Fig. 6A). Substantial numbers of $\operatorname{IgG} 1^{+}$cells were not apparent until the $3^{\text {rd }}$ division in lipid A plus IL-4-stimulated WT B cells and did not occur to a substantial degree in those from MyD88 ${ }^{-/-}$ or $\mathrm{TRIF}^{-/-}$B cells (Fig. 6B, upper). MyD88 ${ }^{-/-}$B cells produced substantial numbers of IgG1 ${ }^{+}$ cells as early as $4^{\text {th }}$ division and steadily increased with each subsequent division in response to lipid A plus IL-4. In contrast, TRIF $^{-/-}$B cells treated with lipid A plus IL-4 had fewer IgG1 ${ }^{+}$ cells $(10 \sim 15 \%)$ in the $4^{\text {th }}$ to $7^{\text {th }}$ division than WT or MyD88 ${ }^{-/-}$B cells. In contrast, B cells from all strains of mice similarly produced $\mathrm{IgG}^{+}$cells in each division in response to anti-CD40 plus IL-4 (Fig. 6B, lower). These results suggest that TRIF signaling may be a requisite for the initiation of the CSR program in the TLR4 plus IL-4-stimulated B cells.

We then considered whether TRIF is required for lipid A plus IL-4-induced activation-induced cytidine deaminase (Aicda) mRNA expression. Lipid A stimulation alone markedly induced Aicda mRNA expression in WT, but this was absent in MyD88 ${ }^{-/-}$B cells (Fig. 6C). TRIF ${ }^{-/-}$B cells were impaired in this response compared with WT B cells. Although the addition of IL-4 slightly increased the level of Aicda mRNA expression in lipid A-stimulated WT B cells in 3 days cultures, Aicda mRNA expression was dramatically augmented by IL-4 stimulation in lipid A-stimulated MyD88 ${ }^{-/-}$B cells in 2 or 3 days cultures. In contrast, this effect of IL-4 was not observed in $\mathrm{TRIF}^{-/-} \mathrm{B}$ cells.

\subsection{TRIF $^{-/-}$mice are impaired in IgG1 production to TNP-LPS, while MyD88 ${ }^{-/-}$mice show increased its production}


We examined serum Ig levels in mice lacking TLR4, MyD88, or TRIF. As reported previously,

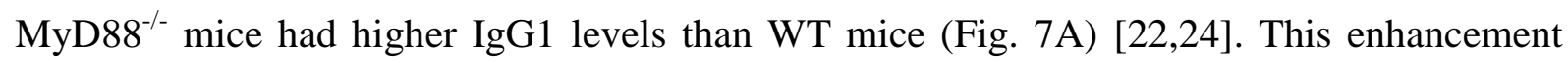
seems to be independent of TLR4-LPS signaling, because TLR $4^{-/-}$mice had normal IgG1 levels. On the other hand, the levels of $\operatorname{IgG} 2 \mathrm{~b}$ and $\operatorname{IgM}$ in $\mathrm{TLR} 4^{-/-}$mice were significantly lower than those in WT mice. MyD88 ${ }^{-/-}$mice had significant decreased IgG2b, IgG3 and IgM levels compared with WT mice. We found no significant alterations in the tested Ig levels in $\mathrm{TRIF}^{-/-}$mice compared with WT mice.

Mice were also immunized with the hapten-conjugated T cell-independent (TI) antigen, TNP-LPS (Fig. 7B). TNP-specific IgG1 production was observed in TNP-LPS-immunized WT mice. TLR $4^{-/-}$mice showed defective its production. The IgG1 production was impaired in $\mathrm{TRIF}^{-/-}$mice, while MyD88 $8^{-/-}$mice exhibited rather increased IgG1 production. TLR ${ }^{-/-}$ mice were impaired in not only IgG1 but also $\operatorname{IgG} 2 \mathrm{~b}, \operatorname{IgG} 3$ and $\operatorname{IgM}$ production in response to TNP-LPS, suggesting that production of these antibodies was completely dependent on TLR4 signaling. Intriguingly, IgG2b and IgG3 production to TNP-LPS was defective in $\mathrm{TRIF}^{-/}$mice.

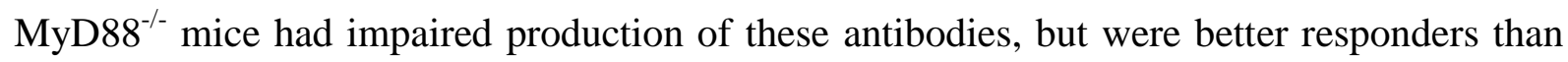
$\mathrm{TRIF}^{-/-}$mice. MyD88 $8^{-/-}$and $\mathrm{TRIF}^{-/-}$mice were similarly impaired in $\mathrm{IgM}$ production to TNP-LPS. TNP-specific IgG2a and IgA were not detected in TNP-LPS-immunized WT mice (data not shown). These results indicate that TRIF pathway positively regulates IgG1 production to TNP-LPS, while MyD88 negatively regulates its production. 


\section{Discussion}

In spite of wide usage of LPS as stimuli in studies of mouse B cells, the mechanism underlying TLR4-dependent B cell responses is still unclear. Here we show that TLR4 differently engages MyD88 and TRIF pathways in response to lipid A or lipid A plus IL-4 in B cells. Upon lipid A stimulation alone, TLR4 preferentially utilizes MyD88 to induce CD86 up-regulation and proliferation in B cells, while TRIF is partially involved in these responses (Fig. 8A). Intriguingly, TLR4 signaling in B cells can be shifted from MyD88-dependent pathway to TRIF-dependent pathway by IL-4 stimulation. TRIF is required for lipid A plus IL-4-induced cell division, Aicda expression, and CSR in B cells (Fig. 8B). These results suggest that TLR4-TRIF signaling may functionally link with IL-4R signaling to induce CSR-associated events. Additionally, IgG production to TNP-LPS, especially IgG2b and IgG3, requires TRIF signaling. The data provided in this study may give important information to understand the B cell activation induced by TLR4.

The previous study has suggested that IgG1 production by LPS plus IL-4 stimulation

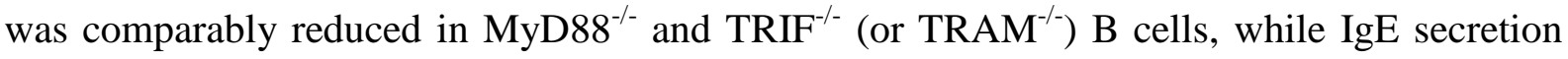
following LPS plus IL-4 stimulation was largely dependent on TRIF [18]. Additionally, cell proliferation and Aicda expression following LPS plus IL-4 stimulation were reduced in

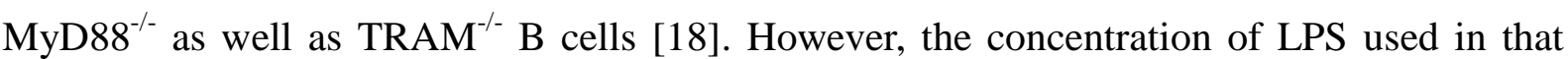
study was relatively high $(10 \mu \mathrm{g} / \mathrm{ml})$ [18]. We used lower and different concentration of lipid A $(0.1-1 \mu \mathrm{g} / \mathrm{ml}$ of lipid A) in the current study and infer from our results that TRIF signaling is critical for IL-4 mediated CSRs, including IgG1, IgE, and IgA, in TLR4-activated B cells. TLR4 plus IL-4-induced cell proliferation and Aicda expression in B cells are also largely dependent on TRIF signaling.

It has been shown that five or more cell divisions of B cells are required for CSR to IgG1 and IgE [25]. Upon anti-CD38 plus IL-5 stimulation, a high number of $\gamma 1-\mu$ switch circles 
was observed in cultured B cells with five to six cell divisions compared with non-divided cells [26]. Decreased cell division most likely contributes to the decreased CSR in response to lipid A plus IL-4. NF- $\kappa \mathrm{B}$ is known to play important roles in B cell proliferation and induction of Aicda expression [27-30]. It is of note that TRIF is required for sustained p65 NF- $\kappa \mathrm{B}$ activation in LPS plus IL-4-stimulated B cells [18]. Thus, NF- $\kappa \mathrm{B}$ activation under TRIF pathway may be important for TLR4 plus IL-4-induced events leading to CSR. Alternatively, TRIF may be important for the initiation of the CSR program induced by TLR4 plus IL-4 stimulation (Fig. 6B). It is now important to clarify signaling molecules and transcriptional factors regulated by TRIF in lipid A plus IL-4-stimulated B cells.

Monophosphoryl lipid A (MPLA) is a detoxified derivative of lipid A and has been associated with the preferential activation of TRIF signaling to enhance $\mathrm{T}$ cell priming and antibody responses against antigens [31]. More recently, cross-linking of BCR and TLR4 by a peptide antigen and MPLA activate TRIF-dependent signaling to induce TI IgG responses [32]. A change from diphosphoryl (in LPS or lipid A) to monophosphoryl (in MPLA) has been considered to trigger TRIF-biased and MyD88-independent TLR4 signaling [33]. In the current study, however, we found that IgG production by the hapten-conjugated LPS, especially IgG2b and IgG3, was largely dependent on TRIF-biased signaling (Fig. 7B). Theses results demonstrated that not only monophosphoryl but also diphosphoryl in LPS or lipid A is associated with TRIF-biased signaling for TI antibody responses. Thus, the number of phosphoryl in lipid A or the low toxicity of MPLA may not be critical for the triggering of TRIF-biased TLR4 signaling. Co-ligation of BCR and TLR4 by TI antigens might allow the induction of TRIF-biased signaling in B cells.

MyD88 in B cells plays a suppressive role in disease models including experimental autoimmune encephalomyelitis and Salmonella typhimurium infection [34,35]. The present study also showed a suppressive role of MyD88 in B cells. MyD88 ${ }^{-/-}$mice had enhanced 
serum IgG1 levels compared with WT mice (Fig. 7A). IgG1 production to TNP-LPS in

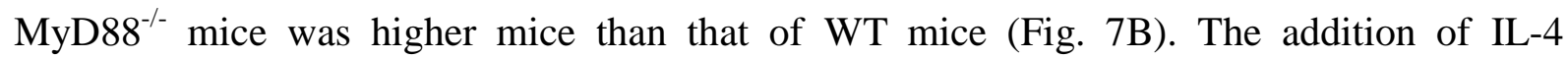
markedly augmented cell division and Aicda expression in lipid A-stimulated MyD88 ${ }^{-/-} \mathrm{B}$ cells compared with WT B cells (Fig. 5A and 6C). Thus, MyD88 may negatively regulate signaling pathway mediated by TLR4 plus IL-4R in B cells. Functional link between MyD88 and TRIF pathways under TLR4 in B cells will be clarified in our future study.

Up-regulation of the co-stimulatory molecules including CD86, CD80, and CD40 by LPS on mouse macrophages is dependent on TRIF [36]. In contrast, lipid A-induced CD86 up-regulation on B cells is largely dependent on MyD88 (Fig. 1A). Up-regulation of such co-stimulatory molecules on macrophages requires LPS-induced type 1 IFN production [36]. To produce type 1 IFN, TLR4/MD-2 needs to be internalized to endosome via membrane CD14 and activate TRIF signaling in myeloid cells [37,38]. Given that membrane CD14 is not expressed on B cells, TLR4/MD-2 might not be internalized by LPS stimulation in B cells. Furthermore, TRIF is unlikely to be involved in TLR4-induced CD86 up-regulation in B cells. It would be interesting to study differences between B cells and macrophages in the expression levels and localization of the TLR4/MD-2 complex and its adaptor molecules, including MyD88 and TRIF.

In conclusion, we identified differential requirements of MyD88 and TRIF under TLR4 signaling in B cells. Results presented in this study provide information about the cooperative roles of TLRs and cytokine receptors in their contribution to innate immune responses against pathogens. In addition, this new information will provide a clue to the development of beneficial immunization strategies. 


\section{Acknowledgments}

We are grateful to Dr. Shizuo Akira (IFRec, Osaka University, Osaka, Japan) for providing us $\mathrm{TLR}^{-{ }^{--}}, \mathrm{MyD}^{-8^{--}}$, and $\mathrm{TRIF}^{-{ }^{--}}$mice. We thank Drs. Masao Kimoto and Shoichiro Ohta for providing us the anti-TLR4 mAb. We thank all members of our laboratories in the University of Toyama and Toyama Prefectural Institute for Pharmaceutical Research for helpful discussions. The authors sincerely thank Toyama Prefecture for supporting our laboratory.

This work was supported by grants from Grant-in-Aid for Scientific Research from the Ministry of Education, Culture, Sports, Science and Technology (MEXT) of the Japanese Government (MEXT KAKENHI Grant Numbers 24117708 and 25126707 to Y.N.) and from the Japan Society for the Promotion of Science (JSPS) (JSPS KAKENHI Grant Numbers 24390119 to K.T., and 24590577 to Y.N.), JST, PRESTO (Y.N.), Hokuriku Innovation Cluster for Health Science, MEXT Regional Innovation Cluster Program, Toyama/Ishikawa Region (K.T.), Hokuriku Life Science Cluster, MEXT Regional Innovation Strategy Support Program (K.T.), Takeda Science Foundation (Y.N.), and Suzuken Memorial Foundation (Y.N.). 


\section{References}

[1] Bendelac A, Bonneville M, Kearney JF. Autoreactivity by design: innate B and T lymphocytes. Nature reviews Immunology 2001;1:177-186.

[2] Rawlings DJ, Schwartz MA, Jackson SW, Meyer-Bahlburg A. Integration of B cell responses through Toll-like receptors and antigen receptors. Nature reviews Immunology 2012;12:282-294.

[3] $\mathrm{Xu} \mathrm{Z,} \mathrm{Zan} \mathrm{H,} \mathrm{Pone} \mathrm{EJ,} \mathrm{Mai} \mathrm{T,} \mathrm{Casali} \mathrm{P.} \mathrm{Immunoglobulin} \mathrm{class-switch} \mathrm{DNA}$ recombination: induction, targeting and beyond. Nature reviews Immunology 2012;12:517-531.

[4] He B, Qiao X, Cerutti A. CpG DNA Induces IgG Class Switch DNA Recombination by Activating Human B Cells through an Innate Pathway That Requires TLR9 and Cooperates with IL-10. The Journal of Immunology 2004;173:4479-4491.

[5] Tsukamoto Y, Nagai Y, Kariyone A, Shibata T, Kaisho T, Akira S, et al. Toll-like receptor 7 cooperates with IL-4 in activated B cells through antigen receptor or CD38 and induces class switch recombination and IgG1 production. Molecular immunology 2009;46:1278-1288.

[6] Xu W, Santini PA, Matthews AJ, Chiu A, Plebani A, He B, et al. Viral Double-Stranded RNA Triggers Ig Class Switching by Activating Upper Respiratory Mucosa B Cells through an Innate TLR3 Pathway Involving BAFF. The Journal of Immunology 2008;181:276-287.

[7] Sonoda E, Matsumoto R, Hitoshi Y, Ishii T, Sugimoto M, Araki S, et al. Transforming growth factor beta induces IgA production and acts additively with interleukin 5 for IgA production. The Journal of experimental medicine 1989;170:1415-1420.

[8] Liu N, Ohnishi N, Ni L, Akira S, Bacon KB. CpG directly induces T-bet expression and inhibits IgG1 and IgE switching in B cells. Nature immunology 2003;4:687-693.

[9] Kawai T, Adachi O, Ogawa T, Takeda K, Akira S. Unresponsiveness of MyD88-deficient mice to endotoxin. Immunity 1999;11:115-122.

[10] Yamamoto M, Sato S, Hemmi H, Hoshino K, Kaisho T, Sanjo H, et al. Role of adaptor TRIF in the MyD88-independent toll-like receptor signaling pathway. Science 2003;301:640-643.

[11] Shimazu R, Akashi S, Ogata H, Nagai Y, Fukudome K, Miyake K, et al. MD-2, a molecule that confers lipopolysaccharide responsiveness on Toll-like receptor 4 . The Journal of experimental medicine 1999;189:1777-1782.

[12] Akashi S, Shimazu R, Ogata H, Nagai Y, Takeda K, Kimoto M, et al. Cutting edge: cell surface expression and lipopolysaccharide signaling via the toll-like receptor 4-MD-2 complex on mouse peritoneal macrophages. Journal of immunology 2000;164:3471-3475. 
[13] Hoshino K, Takeuchi O, Kawai T, Sanjo H, Ogawa T, Takeda Y, et al. Cutting edge: Toll-like receptor 4 (TLR4)-deficient mice are hyporesponsive to lipopolysaccharide: evidence for TLR4 as the Lps gene product. Journal of immunology 1999;162:3749-3752.

[14] Nagai Y, Akashi S, Nagafuku M, Ogata M, Iwakura Y, Akira S, et al. Essential role of MD-2 in LPS responsiveness and TLR4 distribution. Nature immunology 2002;3:667-672.

[15] Barr TA, Brown S, Mastroeni P, Gray D. B cell intrinsic MyD88 signals drive IFN-gamma production from $\mathrm{T}$ cells and control switching to IgG2c. Journal of immunology 2009; 183:1005-1012.

[16] Meyer-Bahlburg A, Khim S, Rawlings DJ. B cell intrinsic TLR signals amplify but are not required for humoral immunity. The Journal of experimental medicine 2007;204:3095-3101.

[17] Groom JR, Fletcher CA, Walters SN, Grey ST, Watt SV, Sweet MJ, et al. BAFF and MyD88 signals promote a lupuslike disease independent of $\mathrm{T}$ cells. The Journal of experimental medicine 2007;204:1959-1971.

[18] Janssen E, Ozcan E, Liadaki K, Jabara HH, Manis J, Ullas S, et al. TRIF signaling is essential for TLR4-driven IgE class switching. Journal of immunology 2014;192:2651-2658.

[19] Adachi O, Kawai T, Takeda K, Matsumoto M, Tsutsui H, Sakagami M, et al. Targeted disruption of the MyD88 gene results in loss of IL-1- and IL-18-mediated function. Immunity 1998;9:143-150.

[20] Miyake K, Yamashita Y, Hitoshi Y, Takatsu K, Kimoto M. Murine B cell proliferation and protection from apoptosis with an antibody against a 105-kD molecule: unresponsiveness of X-linked immunodeficient B cells. The Journal of experimental medicine 1994;180:1217-1224.

[21] Ohta S, Bahrun U, Shimazu R, Matsushita H, Fukudome K, Kimoto M. Induction of long-term lipopolysaccharide tolerance by an agonistic monoclonal antibody to the toll-like receptor 4/MD-2 complex. Clinical and vaccine immunology : CVI 2006;13:1131-1136.

[22] Nagai Y, Kobayashi T, Motoi Y, Ishiguro K, Akashi S, Saitoh S, et al. The radioprotective 105/MD-1 complex links TLR2 and TLR4/MD-2 in antibody response to microbial membranes. Journal of immunology 2005;174:7043-7049.

[23] Nagai Y, Yanagibashi T, Watanabe Y, Ikutani M, Kariyone A, Ohta S, et al. The RP105/MD-1 complex is indispensable for TLR4/MD-2-dependent proliferation and IgM-secreting plasma cell differentiation of marginal zone B cells. International immunology 2012;24:389-400. 
[24] Schnare M, Barton GM, Holt AC, Takeda K, Akira S, Medzhitov R. Toll-like receptors control activation of adaptive immune responses. Nature immunology 2001;2:947-950.

[25] Hasbold J, Lyons AB, Kehry MR, Hodgkin PD. Cell division number regulates IgG1 and IgE switching of B cells following stimulation by CD40 ligand and IL-4. European journal of immunology 1998;28:1040-1051.

[26] Horikawa K, Kaku H, Nakajima H, Davey HW, Henninghausen L, Iwamoto I, et al. Essential Role of Stat5 for IL-5-Dependent IgH Switch Recombination in Mouse B Cells. The Journal of Immunology 2001;167:5018-5026.

[27] Mao CS, Stavnezer J. Differential regulation of mouse germline Ig gamma 1 and epsilon promoters by IL-4 and CD40. Journal of immunology 2001;167:1522-1534.

[28] Dedeoglu F, Horwitz B, Chaudhuri J, Alt FW, Geha RS. Induction of activation-induced cytidine deaminase gene expression by IL-4 and CD40 ligation is dependent on STAT6 and NFkappaB. International immunology 2004;16:395-404.

[29] Snapper CM, Rosas FR, Zelazowski P, Moorman MA, Kehry MR, Bravo R, et al. B cells lacking RelB are defective in proliferative responses, but undergo normal B cell maturation to Ig secretion and Ig class switching. The Journal of experimental medicine 1996;184:1537-1541.

[30] Snapper CM, Zelazowski P, Rosas FR, Kehry MR, Tian M, Baltimore D, et al. B cells from p50/NF-kappa B knockout mice have selective defects in proliferation, differentiation, germ-line $\mathrm{CH}$ transcription, and Ig class switching. Journal of immunology 1996;156:183-191.

[31] Mata-Haro V, Cekic C, Martin M, Chilton PM, Casella CR, Mitchell TC. The vaccine adjuvant monophosphoryl lipid $\mathrm{A}$ as a TRIF-biased agonist of TLR4. Science 2007;316:1628-1632.

[32] Pihlgren M, Silva AB, Madani R, Giriens V, Waeckerle-Men Y, Fettelschoss A, et al. TLR4- and TRIF-dependent stimulation of B lymphocytes by peptide liposomes enables T cell-independent isotype switch in mice. Blood 2013;121:85-94.

[33] Cekic C, Casella CR, Eaves CA, Matsuzawa A, Ichijo H, Mitchell TC. Selective activation of the p38 MAPK pathway by synthetic monophosphoryl lipid A. The Journal of biological chemistry 2009;284:31982-31991.

[34] Lampropoulou V, Hoehlig K, Roch T, Neves P, Gomez EC, Sweenie CH, et al. TLR-Activated B Cells Suppress T Cell-Mediated Autoimmunity. The Journal of Immunology 2008;180:4763-4773.

[35] Neves P, Lampropoulou V, Calderon-Gomez E, Roch T, Stervbo U, Shen P, et al. Signaling via the MyD88 adaptor protein in B cells suppresses protective immunity during Salmonella typhimurium infection. Immunity 2010;33:777-790. 
[36] Hoebe K, Janssen EM, Kim SO, Alexopoulou L, Flavell RA, Han J, et al. Upregulation of costimulatory molecules induced by lipopolysaccharide and double-stranded RNA occurs by Trif-dependent and Trif-independent pathways. Nature immunology 2003;4:1223-1229.

[37] Kagan JC, Su T, Horng T, Chow A, Akira S, Medzhitov R. TRAM couples endocytosis of Toll-like receptor 4 to the induction of interferon-beta. Nature immunology 2008;9:361-368.

[38] Tanimura N, Saitoh S, Matsumoto F, Akashi-Takamura S, Miyake K. Roles for LPS-dependent interaction and relocation of TLR4 and TRAM in TRIF-signaling. Biochemical and biophysical research communications 2008;368:94-99. 


\section{Figure legends}

Fig. 1. Lipid A-induced CD86 up-regulation and B cell proliferation are dependent on MyD88 pathway.

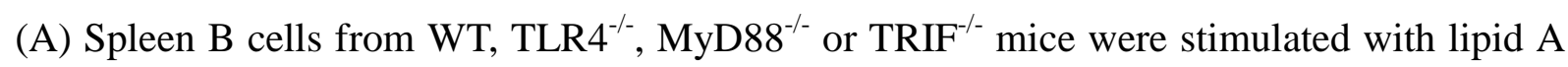
(0.1, $1 \mu \mathrm{g} / \mathrm{ml})$, CpG-B $(1 \mu \mathrm{M}), \mathrm{Pam}_{3} \mathrm{CSK}_{4}(1 \mu \mathrm{g} / \mathrm{ml})$, poly(I:C) $(25 \mu \mathrm{g} / \mathrm{ml})$ or anti-CD40 (1 $\mu \mathrm{g} / \mathrm{ml})$. After $24 \mathrm{~h}, \mathrm{CD} 86$ expression was determined by flow cytometry. Gray and solid lines depict cultured cells stimulated with medium alone and indicated stimulants, respectively. (B)

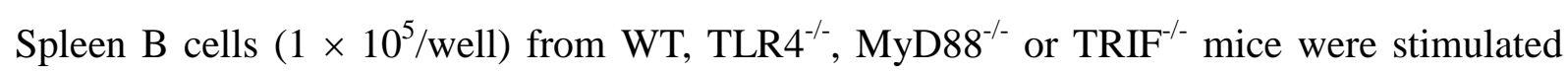
with indicated stimulants. After $72 \mathrm{~h}$, B cell proliferation was determined by ${ }^{3} \mathrm{H}$-Thymidine uptake. Data are shown as means \pm SD. ${ }^{\mathrm{a}} P<0.05$ vs. TLR $4{ }^{-/-},{ }^{\mathrm{b}} P<0.05$ vs. MyD88 $8^{-/-},{ }^{\mathrm{c}} P<0.05$ vs. TRIF $^{-/}$. All data are representative of at least three independent experiments.

Fig. 2. Lipid A plus IL-4-elicited IgG1 and IgE CSRs are impaired in $\mathrm{TRIF}^{-/-} \mathrm{B}$ cells. (A) Spleen B cells from WT, MyD88 $8^{-/-}$or $\mathrm{TRIF}^{-/-}$mice were stimulated with medium alone, lipid A $(0.1,1 \mu \mathrm{g} / \mathrm{ml}), \mathrm{CpG}-\mathrm{B}(1 \mu \mathrm{M}), \operatorname{Pam}_{3} \mathrm{CSK}_{4}(1 \mu \mathrm{g} / \mathrm{ml})$ or anti-CD40 $(1 \mu \mathrm{g} / \mathrm{ml})$ in the presence of IL-4 (25 ng/ml). After $96 \mathrm{~h}$, expression of B220 and IgG1 was determined by flow cytometry. The percentages of $\mathrm{B}_{2} 20^{+} \mathrm{IgG1}^{+}$are indicated. (B) Spleen B cells from WT, $\mathrm{TLR}^{-/-}, \mathrm{MyD}^{-{ }^{-/}}$or $\mathrm{TRIF}^{-/-}$mice were stimulated with medium alone, lipid A $(0.01,0.1,1$ $\mu \mathrm{g} / \mathrm{ml})$ or anti-CD40 $(1 \mu \mathrm{g} / \mathrm{ml})$ in the presence of IL-4 $(25 \mathrm{ng} / \mathrm{ml})$. After 7 days, IgE production in the culture supernatants was determined by ELISA. ${ }^{*} P<0.05$ vs. WT. N.D. depicts not detected. N.S. depicts not significant. All data are representative of at least three independent experiments.

Fig. 3. IL-4-mediated CSR to IgA is impaired in lipid A plus TGF- $\beta$ plus IL-5-stimulated 


\section{TRIF $^{-/-}$B cells.}

(A) Spleen B cells from WT, MyD88 ${ }^{-{ }_{-}}$or $\mathrm{TRIF}^{-l_{-}}$mice were stimulated with combination of the indicated stimulants (lipid A: $10 \mu \mathrm{g} / \mathrm{ml}$, TGF- $\beta$ : $1 \mathrm{ng} / \mathrm{ml}$, IL-5: $5 \mathrm{ng} / \mathrm{ml}$, IL-4: $5 \mathrm{ng} / \mathrm{ml}$ ). After 96 h, expression of B220 and IgA was determined by flow cytometry. The percentages

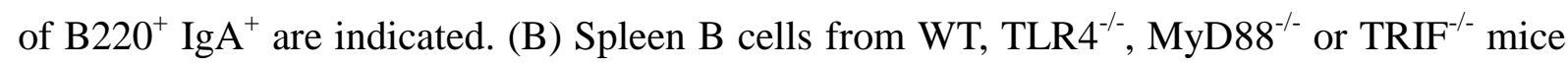
were stimulated with combination of the indicated stimulants (lipid A: $10 \mu \mathrm{g} / \mathrm{ml}$, TGF- $\beta$ : 1 ng/ml, IL-5: $5 \mathrm{ng} / \mathrm{ml}$, IL-4: $25 \mathrm{ng} / \mathrm{ml}$ ). After 7 days, IgA production was determined by ELISA. (C) Spleen B cells from WT, MyD88 ${ }^{-/}$or $\mathrm{TRIF}^{-/-}$mice were stimulated with medium alone or lipid A $(0.01,0.1$ or $1 \mu \mathrm{g} / \mathrm{ml})$. After $96 \mathrm{~h}$, expression of B220 and IgG3 was determined by flow cytometry. The percentages of $\mathrm{B}_{2} 20^{+} \mathrm{IgG}^{+}$are indicated. (D) Spleen B

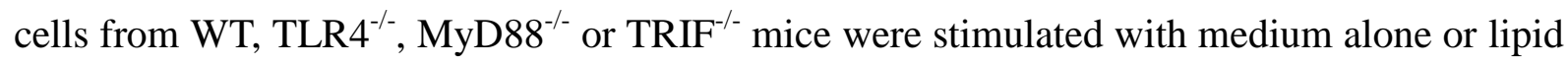
A $(0.01,0.1$ or $1 \mu \mathrm{g} / \mathrm{ml})$. After 7 days, IgG3 production in the culture supernatants was determined by ELISA. Data are shown as means \pm SD. $* P<0.05$, $* * P<0.005$. N.D. depicts not detected. N.S. depicts not significant. All data are representative of at least three independent experiments.

\section{Fig 4. Neither TRIF nor MyD88 pathway is involved in the regulation of IL-4R $\alpha$} expression and IL-4-mediated responses in B cells.

(A) Spleen B cells from WT, MyD88 ${ }^{-/-}$or $\mathrm{TRIF}^{-/-}$mice were stimulated with medium alone, lipid A $(1 \mu \mathrm{g} / \mathrm{ml})$ or anti-CD40 $(1 \mu \mathrm{g} / \mathrm{ml})$. After $24 \mathrm{~h}$, expression of IL-4R $\alpha$ was determined by flow cytometry. Gray and solid lines depict cultured cells stained with isotype control Abs and IL-4R $\alpha$ mAb, respectively. (B) Spleen B cells from WT, MyD88 ${ }^{-/-}$or TRIF $^{-/-}$mice were stimulated with medium alone or IL-4 $(25 \mathrm{ng} / \mathrm{ml})$. After $24 \mathrm{~h}$, expression of CD86 was determined by flow cytometry. Gray and solid lines depict cultured cells stained with isotype control Abs and CD86 mAb, respectively. (C) Purified spleen B cells from WT, MyD88 $8^{-/-}$or 
$\mathrm{TRIF}^{-/-}$mice were stimulated with medium alone, IL-4 $(25 \mathrm{ng} / \mathrm{ml})$, lipid A $(1 \mu \mathrm{g} / \mathrm{ml})$ or lipid A ( $1 \mu \mathrm{g} / \mathrm{ml})$ plus IL-4 (25 ng/ml). After $24 \mathrm{~h}$, expression of P-STAT6 was determined by flow cytometry. Gray and solid lines depict cultured cells stained with isotype control Abs and P-STAT6 mAb, respectively. All data are representative of at least three independent experiments.

\section{Fig. 5. TLR4 plus IL-4-induced cell division is impaired in $\mathrm{TRIF}^{-/-}$B cells.}

(A, B) CFSE-labeled spleen B cells from WT, MyD88 $8^{-/-}$or $\mathrm{TRIF}^{-/-}$mice were stimulated with medium alone, lipid A (1 $\mu \mathrm{g} / \mathrm{ml})$, lipid A $(1 \mu \mathrm{g} / \mathrm{ml})$ plus IL-4 $(25 \mathrm{ng} / \mathrm{ml})$ or anti-CD40 (1 $\mu \mathrm{g} / \mathrm{ml})$ plus IL-4 (25 ng/ml). After $72 \mathrm{~h}$, CFSE fluorescence in viable cells was determined by flow cytometry (A). The values indicate the percentages of divided cells. The relation between the proportion of CFSE positive cells and the cell division was determined (B). Data are shown as means \pm SD. ${ }^{\mathrm{a}} P<0.05$ vs. WT, ${ }^{\mathrm{b}} P<0.05$ vs. $\mathrm{MyD}^{-/-},{ }^{\mathrm{c}} P<0.05$ vs. $\mathrm{TRIF}^{-/-}$. All data are representative of at least three independent experiments.

Fig. 6. TLR4 plus IL-4-induced IgG1 ${ }^{+}$cells per generation and Aicda expression are impaired in TRIF $^{-/-}$B cells.

(A, B) CFSE-labeled spleen B cells from WT, MyD88 $8^{-/-}$or $\mathrm{TRIF}^{-/-}$mice were stimulated with lipid A $(1 \mu \mathrm{g} / \mathrm{ml})$ plus IL-4 $(25 \mathrm{ng} / \mathrm{ml})$ or anti-CD40 $(1 \mu \mathrm{g} / \mathrm{ml})$ plus IL-4 $(25 \mathrm{ng} / \mathrm{ml})$. After 96 h, IgG1 expression was determined by flow cytometry (A). The relation between the proportion of $\operatorname{IgG} 1^{+}$and the cell division was determined (B). Data are shown as means $\pm \mathrm{SD}$. ${ }^{\mathrm{a}} P<0.05$ vs. WT, ${ }^{\mathrm{b}} P<0.05$ vs. MyD88 ${ }^{-/-},{ }^{\mathrm{c}} P<0.05$ vs. $\mathrm{TRIF}^{-/-}$. (C) Spleen B cells from WT,

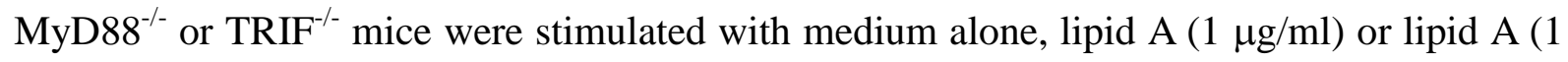
$\mu \mathrm{g} / \mathrm{ml})$ plus IL-4 (25 ng/ml). After 2 or 3 days, total RNA was extracted from cultured cells and expression of Aicda mRNA was examined by RT-qPCR. All data are representative of at 
least three independent experiments.

Fig. 7. IgG1 production to TNP-LPS is impaired in $\mathrm{TRIF}^{-/-}$mice, while $\mathrm{MyD88}^{-/-}$mice exhibit increased its production.

(A) Serum Ig titers were determined by ELISA. Black bars indicate the averages from each

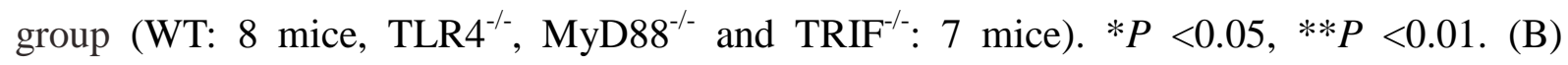
TNP-specific Ab production was determined by ELISA. OD values were shown as means \pm SD in the panels. Each group contained 7 mice. ${ }^{\mathrm{a}} P<0.05$ vs. WT, ${ }^{\mathrm{b}} P<0.05$ vs. $\mathrm{TLR}^{-/-},{ }^{\mathrm{c}} P$ $<0.05$ vs. MyD88 $8^{-/-}$, $P<0.05$ vs. $\mathrm{TRIF}^{-/-}$. All data are representative of at least two independent experiments.

Fig. 8. A hypothetical model of MyD88- or TRIF-dependent B cell responses upon lipid A or lipid A plus IL-4 stimulation.

(A) MyD88 pathway has a major role for lipid A-induced CD86 up-regulation, cell division, and proliferation of B cells. TRIF pathway is required, but not sufficient for these responses. (B) In contrast, lipid A plus IL-4-induced B cell responses, including cell division, Aicda expression, and, $\mu$ to $\gamma 1$ or $\varepsilon$ class switch recombination, are largely dependent on TRIF pathway. TRIF-dependent TLR4 signaling may functionally link with IL-4R signaling. On the other hand, lipid A-stimulated $\mathrm{MyD}^{-8^{--}} \mathrm{B}$ cells are hyper-reactive to IL-4 stimulation compared with WT mice, suggesting that MyD88 pathway may negatively regulate TLR4-TRIF plus IL-4-mediated B cell responses. 


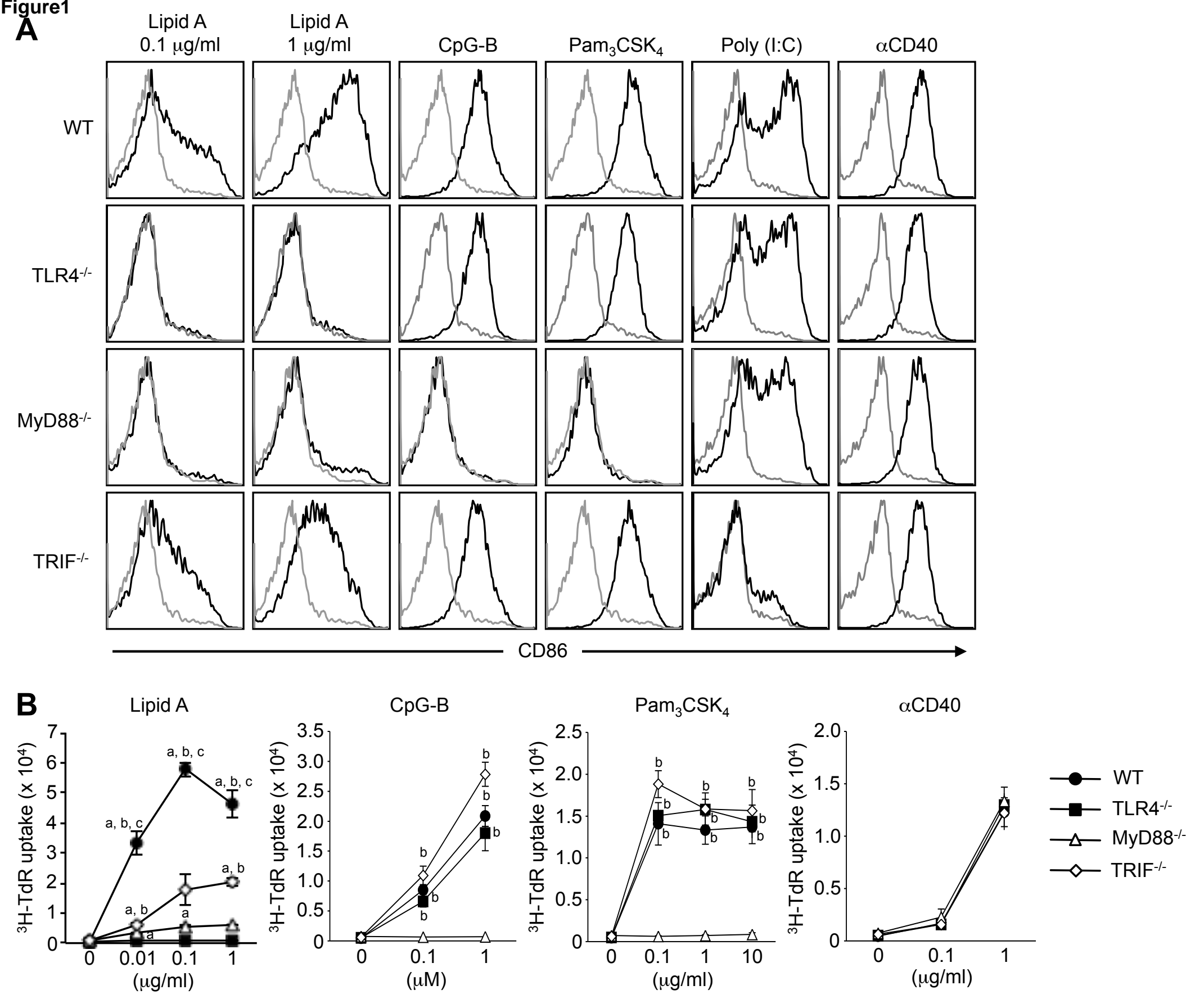


Figure2
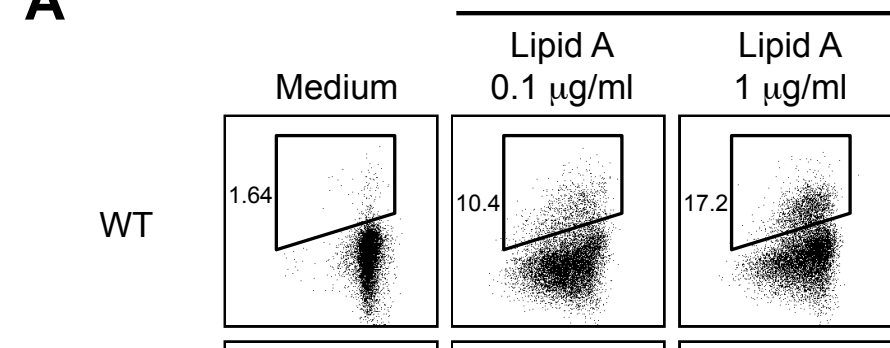

$+\mathrm{IL}-4$

\section{B}

MyD88-/-
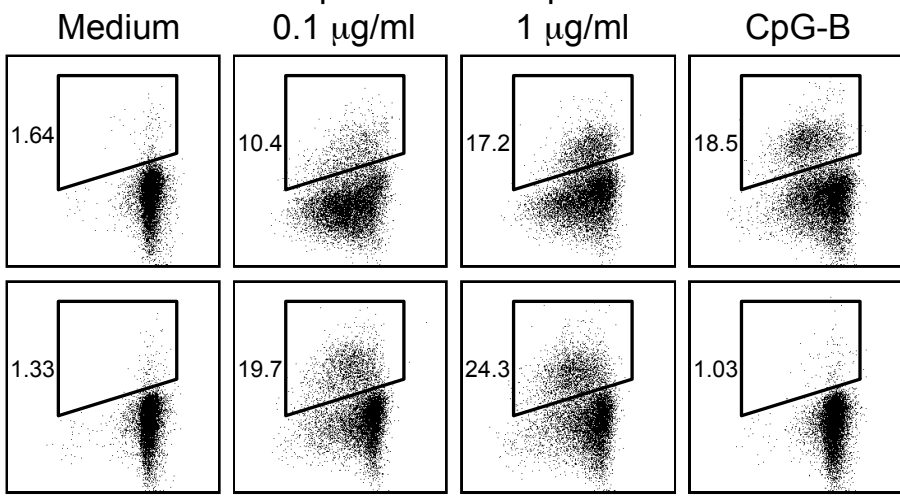

$\mathrm{Pam}_{3} \mathrm{CSK}_{4}$
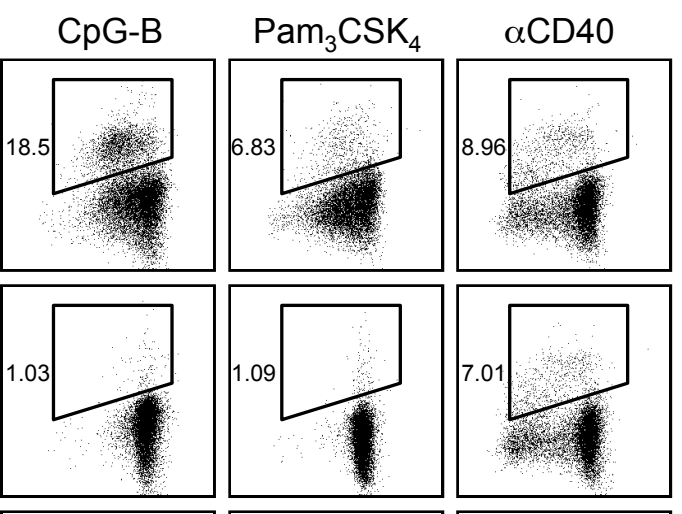

TRIF $^{-1}$
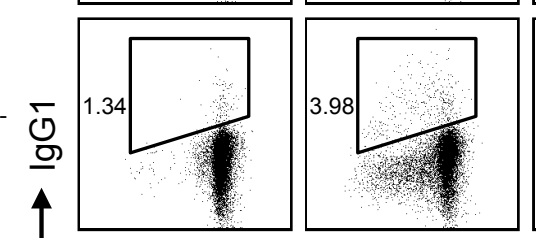

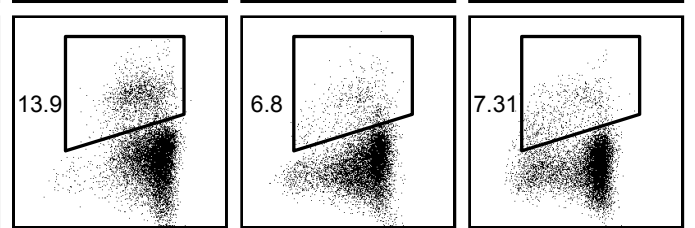

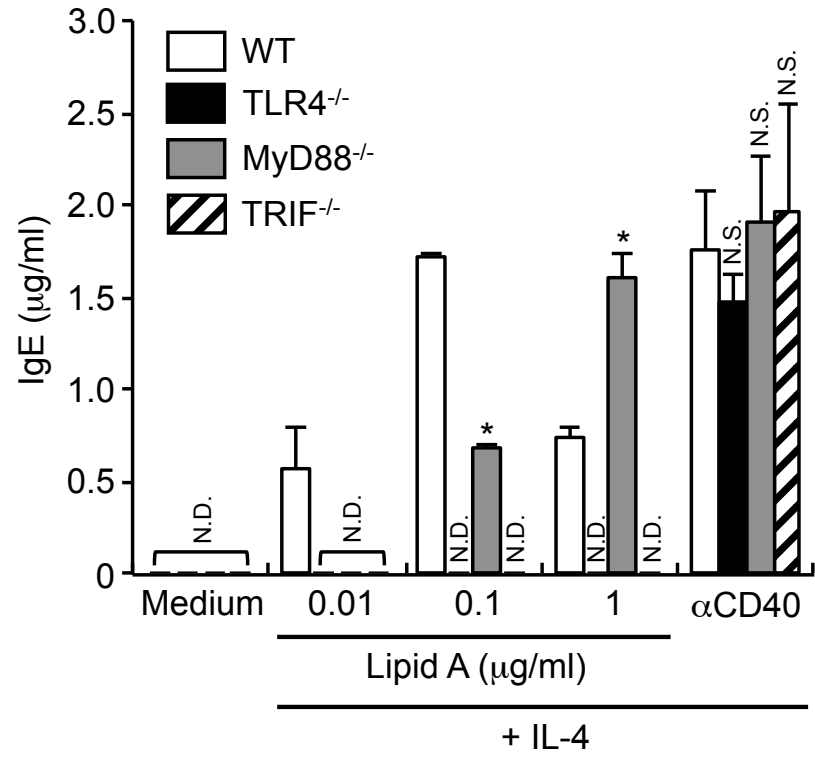




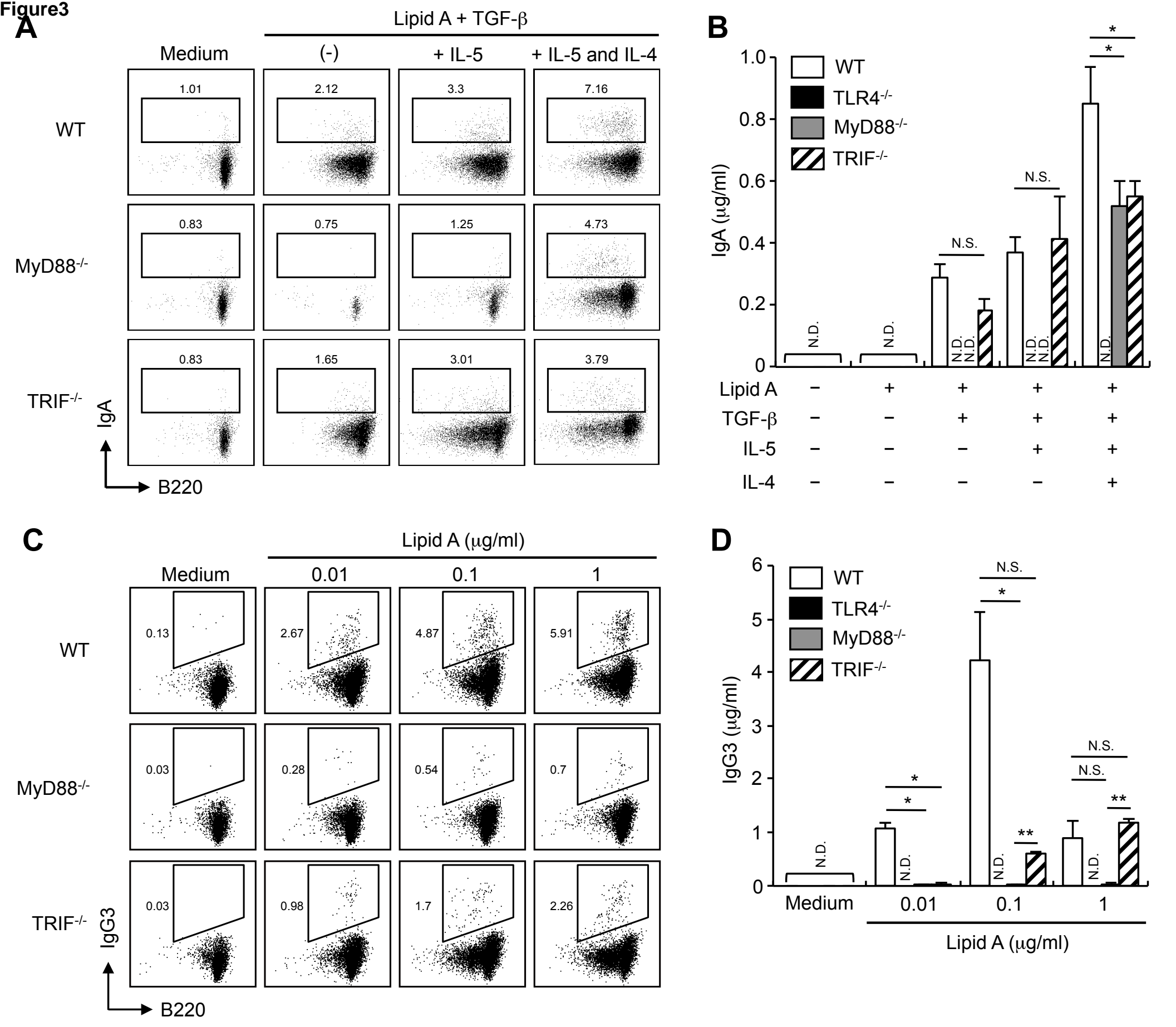


Figure5
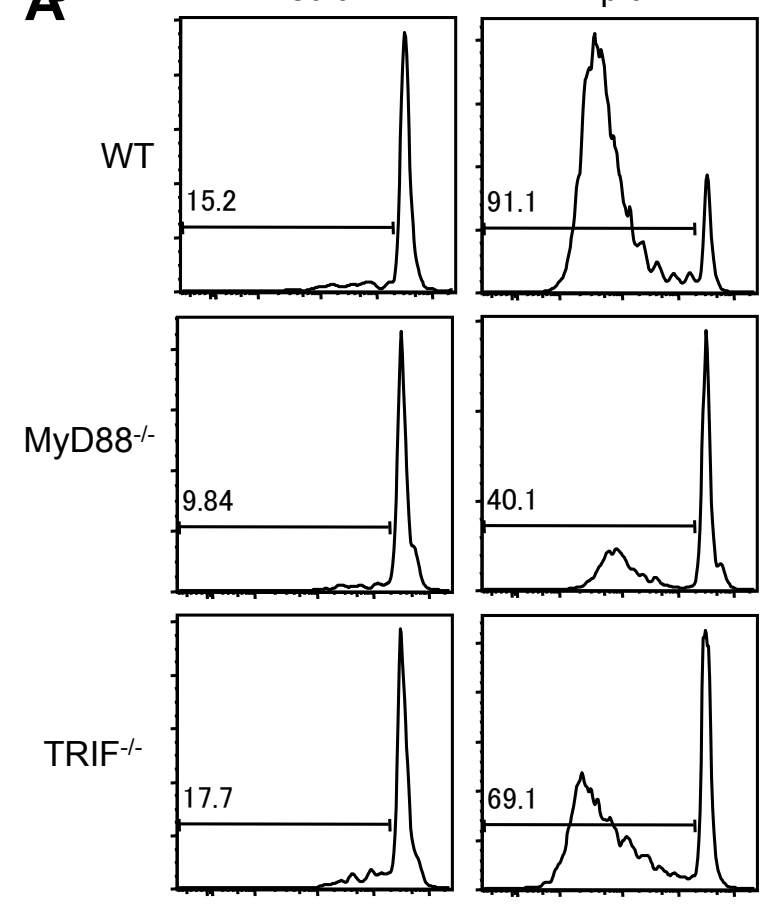

\section{B}

0
0
0
.0
$\frac{0}{0}$
$\frac{0}{0}$
0
0
0
$\frac{\pi}{0}$
$\circ$

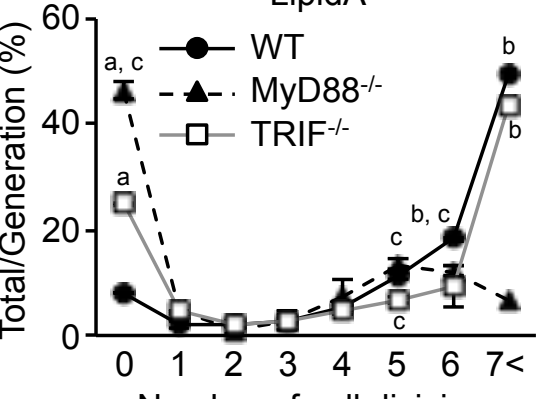

Number of cell division

LipidA
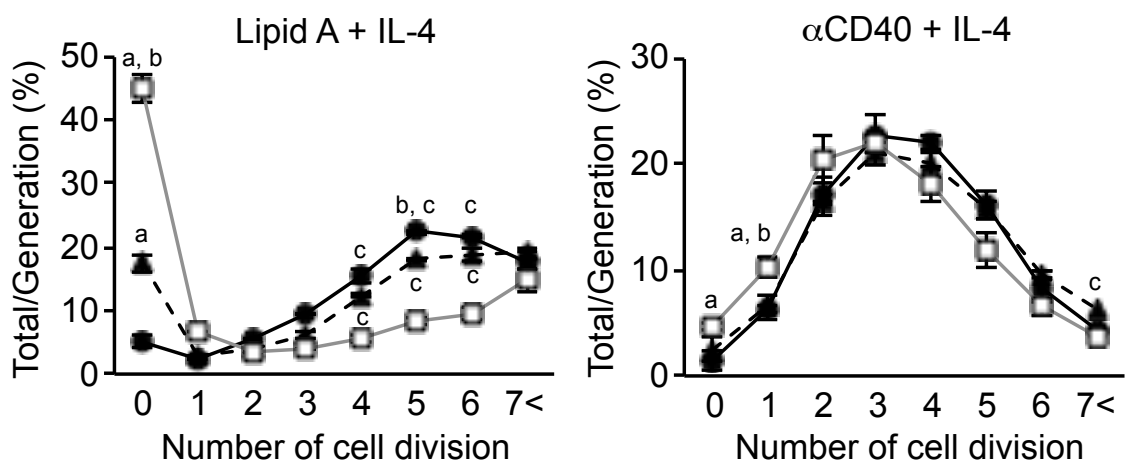

Number of cell division
Lipid A + IL-4
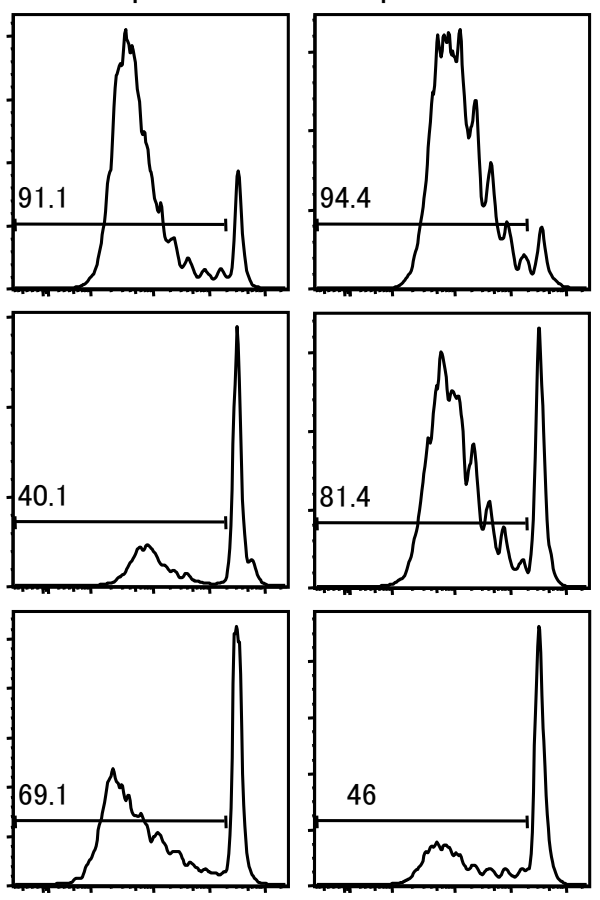

CFSE
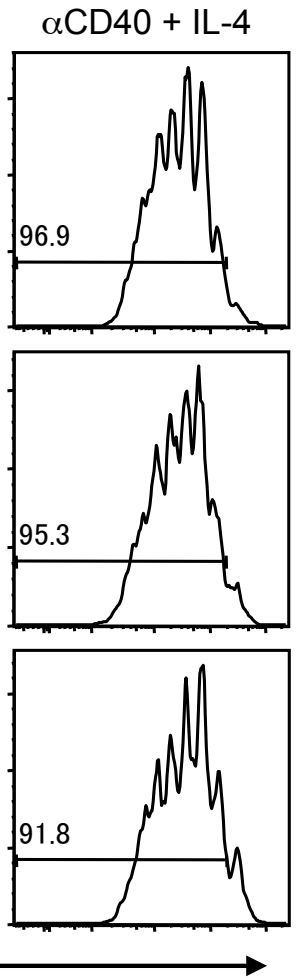
Fipure6

MyD88-1-

WT
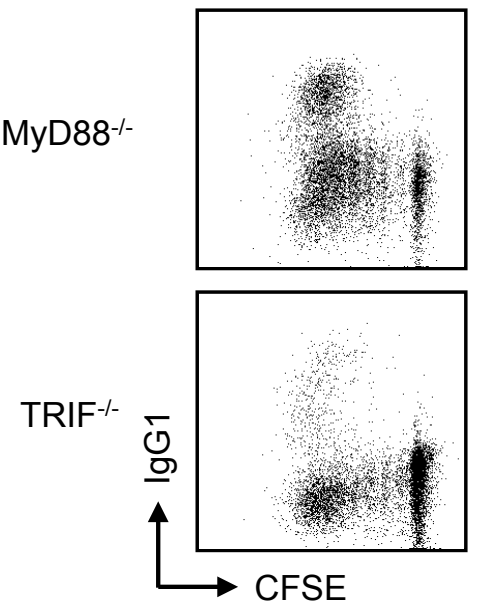

B Lipid A + IL-4
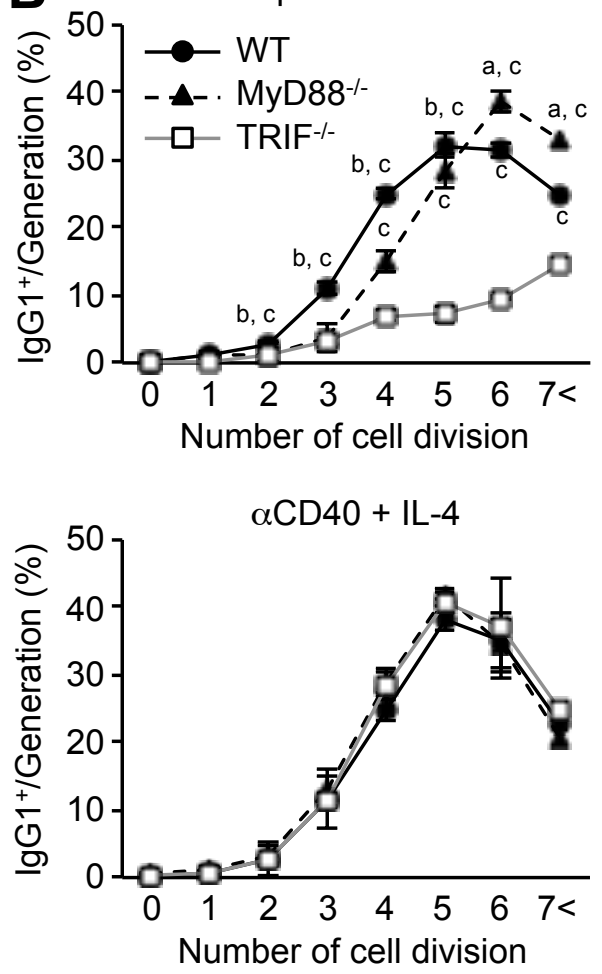

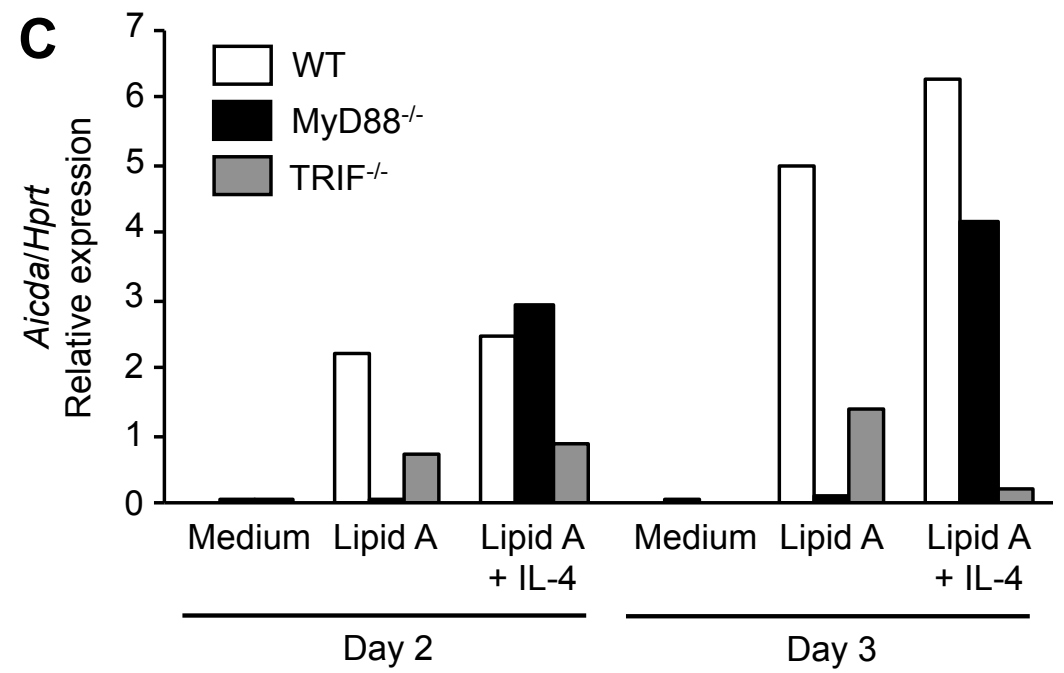



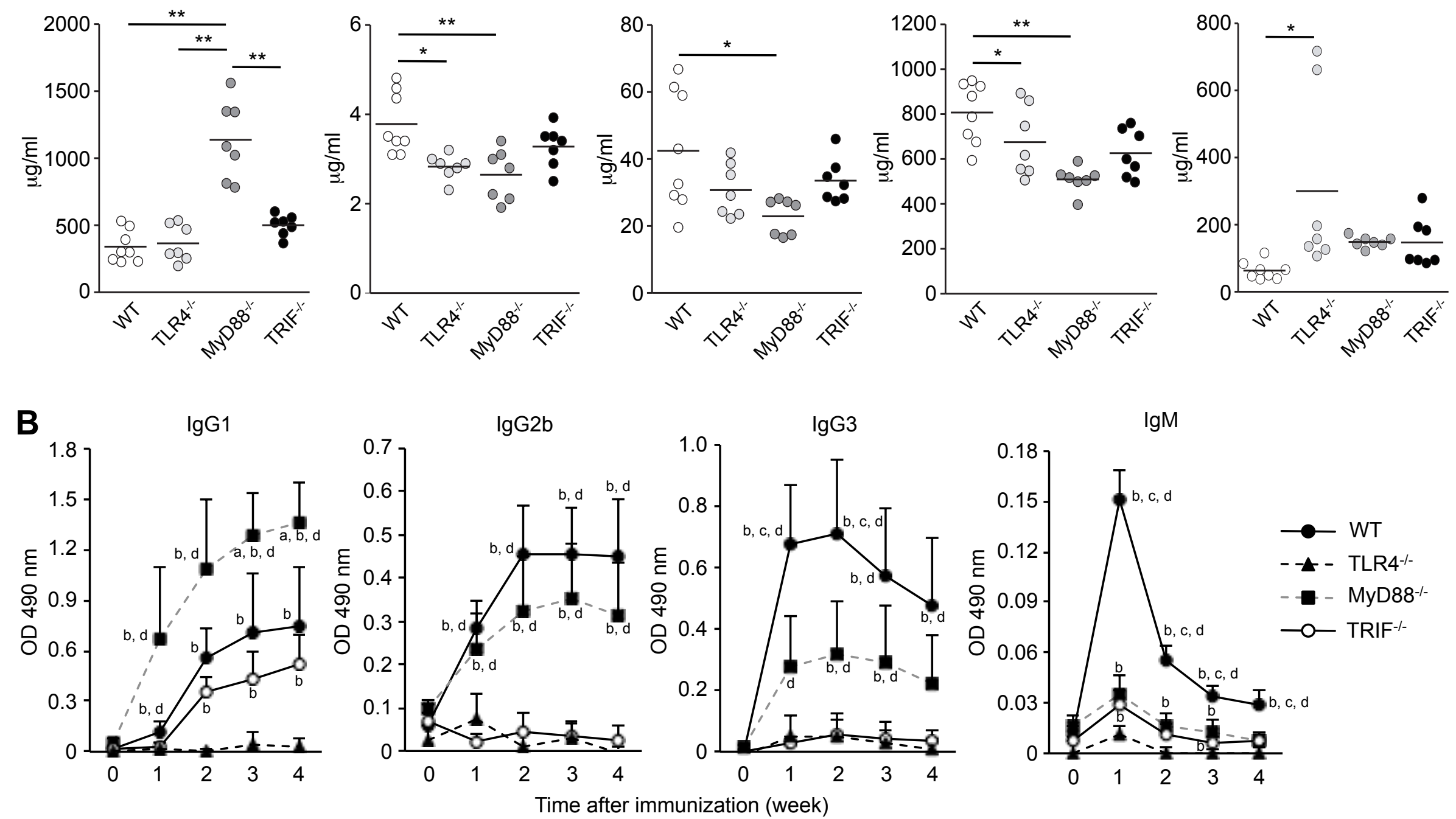


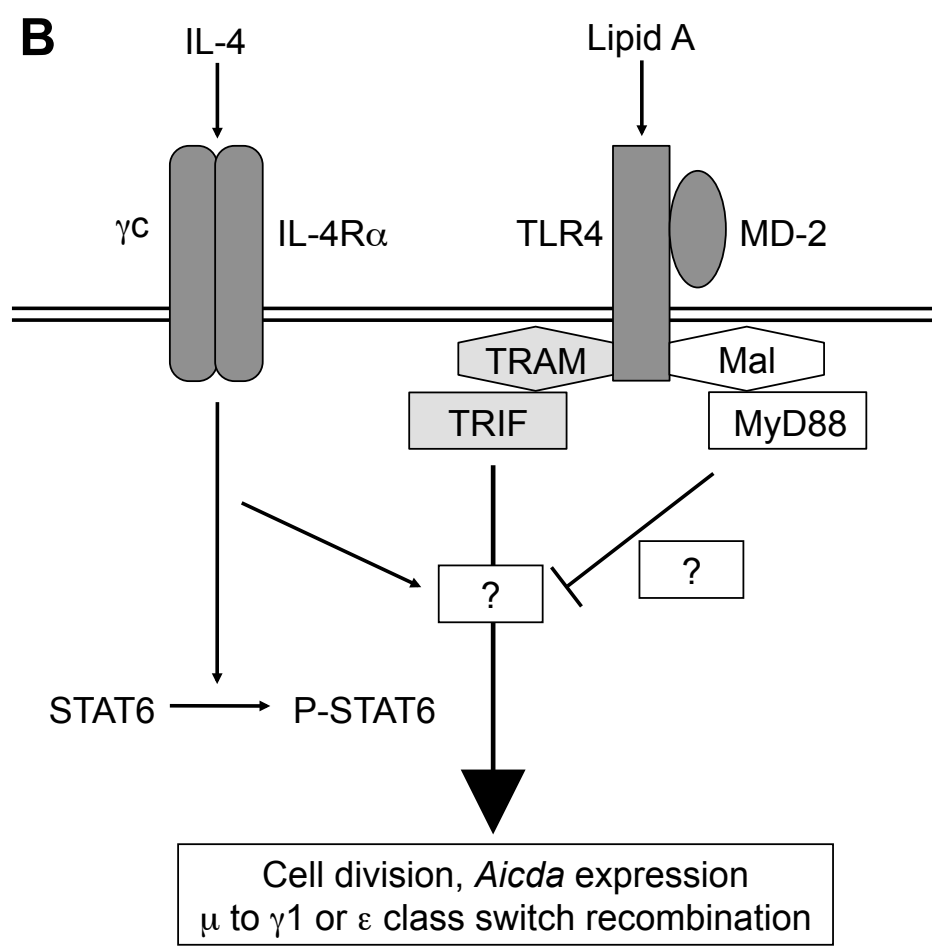

